\title{
Unilateral Pulmonary Fibrosis in Pregnancy: A Post-Tubercular Sequelae
}

\author{
Tanishq S. Sharma ${ }^{1}$, Shivang Amin ${ }^{2}$, Shilpa Sapre ${ }^{2}$, Palak Golani ${ }^{2}$, Sheetalba Zala ${ }^{2}$ \\ 1. Medicine, Shree Krishna Hospital, Anand, IND 2. Obstetrics and Gynaecology, Pramukhswami Medical College, \\ Anand, IND
}

Corresponding author: Tanishq S. Sharma, sharma.tanishqtask@gmail.com

\begin{abstract}
Pulmonary tuberculosis (TB) is one of the top 10 leading causes of death in the world. Multi-drug resistant TB can lead to short-term and long-term sequelae causing clinical, psychosocial, and financial burden on the diseased. Pregnancy in a woman with compromised pulmonary function is a challenge for the treating obstetrician. A multidisciplinary approach involving a respiratory physician, pre-conceptional counseling, and delivery at a tertiary care center can reduce maternal morbidity and mortality. Compliance with antitubercular treatment with regular follow-up can minimize the long term effects of pulmonary TB.
\end{abstract}

We report a case of unilateral lung collapse due to multidrug-resistant pulmonary TB in pregnancy with good maternal and fetal outcomes.

Categories: Family/General Practice, Obstetrics/Gynecology, Pulmonology

Keywords: : pregnancy, pulmonary fibrosis, multi-drug resistant tb, sequelae, maternal outcome, fetal outcome

\section{Introduction}

Multi-drug resistance [1] tuberculosis (TB) is a form of TB wherein there is no response to the two most effective anti-tubercular medicines, isoniazid, and rifampicin. It can lead to short term and long term sequelae [2] like pleural thickening with fibrosis, bronchiectasis, aspergilloma, and bronchogenic carcinoma. Physiological changes in the respiratory system add a significant burden in patients with pulmonary fibrosis.

We report here a case of a pregnant woman with left-sided pulmonary fibrosis secondary to multi-drug resistant TB. There are a few case reports of pregnant women with unilateral pulmonary fibrosis due to pulmonary TB [3].

\section{Case Presentation}

A 24-year-old primigravida was referred at 36 weeks of gestation for institutional delivery. She had no

Review began $11 / 16 / 2020$ Review ended 11/27/2020 Published 12/03/2020

\section{○ Copyright 2020}

Sharma et al. This is an open access article distributed under the terms of the Creative Commons Attribution License CC-BY 4.0., which permits unrestricted use, distribution, and reproduction in any medium, provided the original author and source are credited. complaints of bleeding or leaking per vaginum and had taken regular antenatal visits. She was asymptomatic at the time of her visit.

The patient gave a history of pulmonary TB in childhood for which she received anti-tubercular treatment. She defaulted to the first course of treatment but later when she again developed symptoms full antitubercular treatment was taken. On detailed evaluation and confirmation by acid-fast bacilli culture sensitivity, it was found that the patient had developed multi-drug resistant $\mathrm{TB}$ as she was a chronic defaulter. Pulmonary function tests done in 2010 reported severe obstructive respiratory disease and moderate restrictive respiratory disease. The patient was referred to a higher center for pneumectomy, however, she did not go forward with the operation. The patient did not come for follow-up in the chest medicine department for the last six years.

Her family and social history were unremarkable. Counseling regarding the mode of delivery and the need for intensive care was discussed with the patient and her relatives.

On general examination, pulse was 90/min, blood pressure was 110/70mm of $\mathrm{Hg}$, her $\mathrm{SpO} 2$ was $98 \%$. No pallor, cyanosis, icterus, clubbing, or lymphadenopathy was seen. Examination of her respiratory system revealed dullness to percussion on the left side and on auscultation there were crackles and decreased air entry and vocal resonance over the left hemithorax. Despite these findings, the patient had no complaints of breathlessness or cough. The obstetric examination was normal and corresponding with the gestational age. Following lab investigations were additionally done which all ended up being within normal limits (Table 1). 


\section{Cureus}

\begin{tabular}{|c|c|c|c|c|c|c|c|c|}
\hline $\begin{array}{l}\text { Total Leukocyte count } \\
\text { (x1000/ul) }\end{array}$ & $\begin{array}{l}\text { Red blood cell count } \\
\text { (million/cmm) }\end{array}$ & Haemoglobin (g/dl) & Haematocrit (\%) & $\begin{array}{l}\text { Mean corpuscular } \\
\text { volume (fl) }\end{array}$ & $\begin{array}{l}\text { Mean } \\
\text { corpuscular } \\
\mathrm{HB}(\mathrm{pg})\end{array}$ & $\begin{array}{l}\text { MCHC } \\
(\mathrm{g} \%)\end{array}$ & $\begin{array}{l}\text { RDW } \\
\text { (fl) }\end{array}$ & $\begin{array}{l}\text { Platelet count } \\
\text { (x1000/ul) }\end{array}$ \\
\hline 11.7 & 4.43 & 12.3 & 36.6 & 82.6 & 27.8 & 33.6 & 37.8 & 272 \\
\hline
\end{tabular}

\section{TABLE 1: Laboratory Investigations on admission}

HB: haemoglobin; MCHC: mean corpuscular hemoglobin concentration; RDW: red cell distribution width.

On the radiograph of the chest with an abdominal shield taken in the posteroanterior view, there was evidence of diffuse radio-opacity involving left hemithorax with multiple small round to oval radiolucencies involving left mid-lower zones and mild emphysematous changes in the right lung (Figure 1).

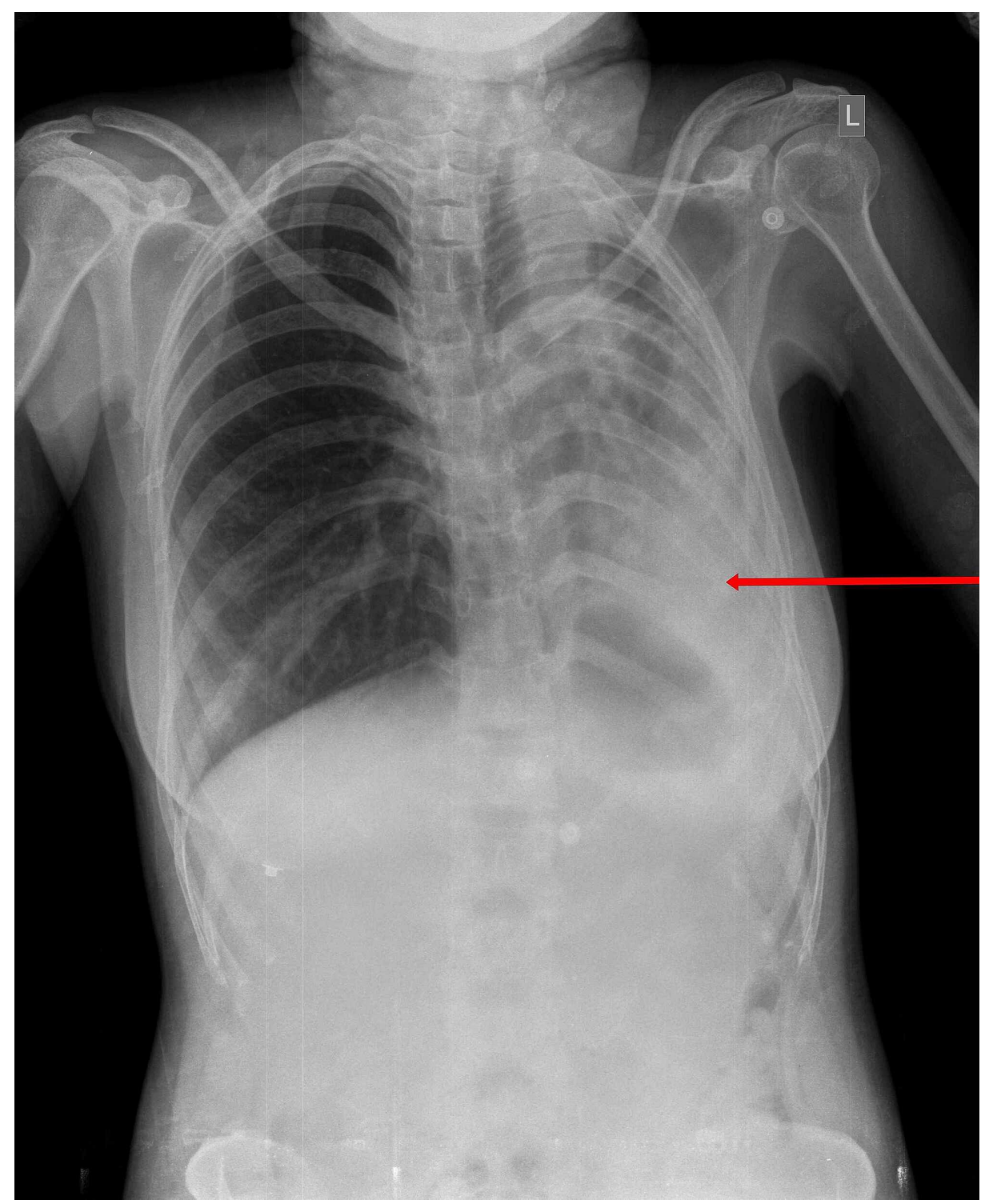

FIGURE 1: Chest radiograph, posteroanterior view, showing unilateral left side post tuberculosis fibrosis

On ultrasound scan, the findings were indicative of a single live intrauterine fetus with an average gestational age of 36 weeks and 5 days $+/-2$ weeks and four days in cephalic presentation. One week after admission, patient went into labor but refused normal vaginal delivery; hence, a full-term lower segment 
cesarean section under spinal anesthesia was planned on maternal request. There were no anesthetic complications and a healthy female baby of $2.6 \mathrm{~kg}$ body weight was delivered with an Apgar score of 9 and 10 at one and five minutes respectively. She and her baby are doing well after the delivery.

\section{Discussion}

Drug resistance in pulmonary TB develops either due to premature discontinuation or improper antitubercular treatment. In 2020, the World Health Organization (WHO) has recommended a newer, shorter oral regimen for patients with Multi-drug resistant TB [4]. This regimen is for 9-11 months as compared to the older longer regimen of 20 months. Multi-drug resistant TB can lead to a debilitating effect on the airway, lung parenchyma, chest wall, pleura, pulmonary vasculature, and mediastinum. Parenchymal involvement is more common. Cicatrization collapse or fibrosis usually occurs because of partial or complete involvement of lung parenchyma and airway. Radiologically there is an area of alveolar destruction with loss of lung volume and ipsilateral mediastinal shift [5]. These can be symptomatic or asymptomatic like our patient was asymptomatic. Pregnancy adds a burden on the already compromised respiratory system, particularly during labor. Anaesthetic complications particularly general anesthesia during cesarean section can risk the life of the mother and her baby [6].

\section{Conclusions}

TB is a major concern in developing countries and even if a bacterial cure has been achieved, there could be short-term and long-term sequelae. Compliance with treatment with regular follow-up can minimize the post-tubercular sequelae in the reproductive age group. Pre-conceptional counseling, regular antenatal care coupled with a multidisciplinary approach is the key to successful outcomes. If appropriate and timely treatment is not taken, it can lead to serious debilitating irreversible outcomes. In this case, such an adverse outcome was unilateral post TB fibrosis which could have been a major problem for the normal pregnancy to continue. So the early diagnosis and management of TB hold much importance to prevent deleterious impact on the psychosocial and financial aspects of the patient.

\section{Additional Information \\ Disclosures}

Human subjects: Consent was obtained by all participants in this study. Conflicts of interest: In compliance with the ICMJE uniform disclosure form, all authors declare the following: Payment/services info: All authors have declared that no financial support was received from any organization for the submitted work. Financial relationships: All authors have declared that they have no financial relationships at present or within the previous three years with any organizations that might have an interest in the submitted work. Other relationships: All authors have declared that there are no other relationships or activities that could appear to have influenced the submitted work.

\section{Acknowledgements}

The authors would like to acknowledge Dr. Rajan Patel for his contribution to the radiograph reporting.

\section{References}

1. CDC: drug-resistant TB guidelines . (2019). Accessed: November 1, 2020: https://www.cdc.gov/tb/publications/guidelines/mdr_tb.htm.

2. Ali MG, Muhammad ZS, Shahzad T, Yaseen A, Irfan M: Post tuberculosis sequelae in patients treated for tuberculosis: an observational study at a tertiary care center of a high TB burden country. Eur Respir J. 2018, 52:2745. 10.1183/13993003.congress-2018.PA2745

3. Masukume G, Sengurayi E, Moyo P: Massive hemoptysis and complete unilateral lung collapse in pregnancy due to pulmonary tuberculosis with good maternal and fetal outcome: a case report. BMC Res Notes. 2013, 6:335. 10.1186/1756-0500-6-335

4. WHO consolidated guidelines on tuberculosis, Module 4: treatment - drug-resistant tuberculosis treatment . (2020). Accessed: June 15, 2020: https://www.who.int/publications/i/item/9789240007048.

5. Khan R, Malik NI, Razaque A: Imaging of pulmonary post-tuberculosis sequelae. Pak J Med Sci. 2020, 36:S75-S82. 10.12669/pjms.36.ICON-Suppl.1722

6. Jadon A: Complications of regional and general anaesthesia in obstetric practice . Indian J Anaesth. 2010, 54:415-420. 10.4103/0019-5049.71039 